\title{
A DIMENSÃO ESPACIAL DA EXISTÊNCIA E AS GEOGRAFICIDADES: SOBRE OS SENTIDOS E O FUNDAMENTO GEOGRÁFICO DA AÇÃO POLÍTICA
}

\author{
Mario Alberto dos Santos \\ Universidade Federal do Oeste da Bahia, Centro das Humanidades, Barreiras, BA, Brasil \\ mario.alberto@ufob.edu.br \\ Catherine Prost \\ Universidade Federal da Bahia, Programa de Pós-Graduação em Geografia, Salvador, BA, Brasil \\ cprost@ufba.br
}

\begin{abstract}
RESUMO
No presente artigo admite-se que a dimensão espacial da existência adquire sentido nas interações e relações cotidianas por meio das experiências e da cognição humana. Esses fenômenos estão ligados à construção de nossas geograficidades, e propiciam a pluralidade inerente à vida social. Assim, na concepção fenomênica do mundo, o sentido atribuído ao espaço é determinado por um ato de significação humana. Para a ação política, esse espaço é o da aparência, e como a pluralidade humana é conditio sine qua non dessa ação, a coexistência de ontologias evidencia-se por meio dos sentidos e do fundamento geográficos intrínsecos à ação. Portanto, o aparecer constitui-se no ato que impõe ao agente-sujeito Ser ao agir no espaço da aparência. Considera-se o fundamento geográfico da ação política o próprio espaço onde ela se realiza, e o seu sentido geográfico as geograficidades inerentes aos agentes-sujeitos responsáveis pela sua materialização na vida cotidiana. Ao propor a centralidade na ontologia existencial do Ser, as geograficidades como o fenômeno que traduz as mais profundas e íntimas relações e interações humanas com a Terra, tornam-se essenciais para a própria concepção e realização da ação política, visto que tal fenômeno tem na espacialidade intrínseca ao Ser sua constituição e sentido.
\end{abstract}

Palavras-chave: Espacialidades. Sentido de Ser. Vida Cotidiana. Relações cognitivas. Experiências vividas.

\section{THE SPATIAL DIMENSION OF EXISTENCE AND THE GEOGRAPHIES: ABOUT THE MEANING AND THE FUNDAMENT GEOGRAPHIC OF POLITICS ACTION}

\begin{abstract}
In the present article we see that the spatial dimension of existence acquires meaning in the interactions and daily relations through human experiences and cognition. These phenomena are linked to the construction of our geographies, and propitiate the inherent plurality of social life. Thus, in the phenomenal conception of the world, the meaning attributed to space is determined by an act of human signification. For political action, this space is that of appearance, and as human plurality is conditio sine qua non of this action, the coexistence of ontologies is evidenced through the geographical senses and basis intrinsic to the action. Therefore, appearing is constituted in the act that it imposes on the subject-agent Being to act in the space of appearance. The geographical basis of political action considers the very space where it is realized, and its geographic sense and the geographies inherent to the agent-subjects responsible for its materialization in everyday life. In proposing centrality in the existential ontology of Being, geographies as the phenomenon that translates the deepest and most intimate human relations and interactions with Earth, become essential for the conception and realization of political action, since such phenomenon has in the intrinsic spatiality to Being its constitution and meaning.
\end{abstract}

Keywords: Spatialities. Sense of Being. Daily Life. cognitive relations. life experiences. 


\title{
INTRODUÇÃO
}

A trajetória do pensamento geográfico frente às reflexões e debates a respeito do fenômeno do espaço foi (e ainda é) trilhada a partir da pluralidade de sentidos e compreensões atribuídas ao mesmo. Portanto, para a geografia, pensar o espaço, significa pensar sobre uma das dimensões de nossa realidade intersubjetiva, o que leva à compreensão de como as experiências de relações e interações cognitivas e ontológicas são essenciais ao sentido que lhes é atribuído. São nelas e a partir delas que identificamos significantes dando-Ihes significados e sentido para a vida humana e sua espacialidade intrínseca.

Acessar e compreender a dimensão espacial da existência, por meio da experiência ontológica e existencial, é possível com a realização das atividades do espírito, dos sentidos humanos e das relações e interações cognitivas com o mundo. Por isso, a preocupação central desse artigo é o entendimento desse mesmo mundo, a partir de sua concepção fenomênica para pensar sobre ação política e espaço na Geografia. Logo, ter nas geograficidades o fenômeno da vida cotidiana, que traduz nossa mais íntima e profunda relação com a Terra, implica em transpor a existência humana para a coexistência com o outro, pois se trata da vida compartilhada no cotidiano vivido. As geograficidades nascem num mundo de significados e significantes já pré-estabelecido e de condutas e relações sociais válidas. Deste modo, a realização do Dasein na existência do Ser nunca é isolada desse mundo compartilhado, o que a torna, nesse caso, coexistência com outros. Isso justifica pensar o espaço como a dimensão social do encontro de multiplicidades e diferentes trajetórias de experiências vividas.

As geograficidades se apresentam como o fenômeno que traduz um sentido de Ser em sua coexistência cotidiana. Por isso a ação. É ao agir que o Ser do agente se revela no, e pelo espaço. Tendo como fundamento as reflexões de Hannah Arendt (2014) sobre as atividades da condição humana de existência, o fenômeno da ação se destaca com maior substancialidade no pensamento geográfico a partir da década de 1980. Desde esse período houve vários estudos e pesquisas aprofundando a compreensão geográfica sobre o fenômeno da ação, para pensar a construção de um sentido para o espaço e para o cotidiano que nele se realiza e materializa. Por isso, consideramse as geograficidades o fenômeno que garante um sentido geográfico à ação, e o espaço o fenômeno que a fundamenta.

O caminho filosófico-epistemológico aqui eleito se evidencia no título do ensaio e caracteriza-se na Geografia Humanista Fenomenológica. Há ainda a colaboração de proposições explicativas trazidas pela Ciência da Cognição a respeito de fenômenos e processos gerativos e constitutivos das experiências de relações e interações cognitivas entre ser humano e mundo. Isso implica considerar preceitos relacionados à nossa maneira de conhecer e explicar o que se conhece. Deste modo, é essencial ao falar da coexistência de geograficidades e ontologias com vistas à ação política, falar da dialogicidade de experiências e vivências no cotidiano.

\section{O ESPAÇO E A ESPACIALIDADE NA CONSTITUIÇÃO DE UM SENTIDO DE SER: SOBRE GEOGRAFICIDADES, SABERES E EXPERIÊNCIAS}

As reflexões sobre espaço e espacialidade na realização do ser-no-mundo tem como base considerar os saberes e os fazeres na compreensão de um sentido de Ser, o qual se realiza a partir da coexistência espacial cotidiana. Tal coexistência é ao mesmo tempo existência no mundo, pois o mundo é o lugar de sua realização e ambiência. Porém, é também existência com o mundo, visto que há uma dinâmica de relações e interações vividas e partilhadas com esse mundo circundante que condicionam sua realização e sentido. Assim,

\begin{abstract}
Mundo é efetivamente uma totalidade, muito mais a título de horizonte do que de realidade dada. É um horizonte global e presuntivo de sentido que é relativo ao projeto do Dasein (pre-sença), e nesse horizonte os objetos e os seres têm lugar porque como dado primordial eles recebem um significado. (BESSE, 2011, p.115).
\end{abstract}

O espaço é, portanto, um fenômeno da percepção humana, intimamente relacionado com o mundo vivido; a dimensão e as relações espaciais aparecem no conviver cotidiano. Importa-nos o papel da imensidão íntima e a relação entre casa e universo (mundo) quando Bachelard (1989) apresenta argumentos que são também construídos a partir de uma concepção fenomênica do mundo para refletir sobre a poética do espaço. Isso leva novamente a pensar sobre o espaço, a ação política e o viver social, fundado na realização da ontologia existencial e das experiências dos agentes-sujeitos nesse espaço. De fato, ao transcender a geometria tangível e matematizável dos espaços e

$\begin{array}{llllll}\text { Caminhos de Geografia } & \text { Uberlândia - MG } & \text { v. 19, n. 67 } & \text { Set/2018 } & \text { p. 83-98 } & \text { Página } 84\end{array}$


compreender a dinâmica social e política que os constituem e os significam, abre-se um cenário favorável para não tratar, de um lado, o agir político como uma mera fabricação de um objeto, e de outro lado, o viver social como uma mera doutrinação de comportamentos institucionalizados. Isso define a liberdade política como princípio básico dos viveres sociais.

O espaço, assim, não é mais esse meio das coisas simultâneas que poderia ser dominado por um observador absoluto, igualmente próximo de todas elas, sem ponto de vista, sem corpo, sem situação espacial [...]. (MERLEAU-PONTY, 2004, p.15).

O espaço é antes de tudo um significado atribuído, um ato intencional da, e na experiência. Compreende-se que há no cotidiano inúmeras situações consideradas como problemas sociais e que possuem íntima relação com a forma do nosso comportamento espacial (WERLEN, 2000). Doreen Massey $(2013$, p.35) tece reflexões "[...] sobre o espaço ordinário, o espaço e os lugares através dos quais, na negociação de relações dentro da multiplicidade, o social é construído.". Nessas negociações há demandas por ressignificações de valores, relações e interações para a coexistência cotidiana da pluralidade humana fazer sentido.

Nos estudos e reflexões de Dardel (2011) sobre o sentido do espaço para a Geografia, o autor propõe adjetivações para dar sentido aos diferentes sentidos que o espaço possui para a percepção humana. Questiona-se, portanto, a matematização do pensar sobre o espaço, quando colocado enquanto fenômeno fixo e passivo diante da existência humana. Esse ponto encontra abrigo nos estudos de Massey (2013), o que invoca retomar as reflexões sobre o sentido de espaço com seus desdobramentos na política. A autora entende o pensar sobre o espaço considerando três aspectos fundamentais: produto de inter-relações, condição de existência da multiplicidade e que, como processo, está em eterna construção.

Deste modo, pensar sobre diferentes fenômenos e processos que envolvem a existência humana de ser-no-mundo é entrar no universo de possibilidades criado nos domínios fenomênicos da cognição e da ação. As relações e interações realizadas no cotidiano dependem da dimensão espacial dessa existência. Os fenômenos percebidos e experienciados a partir de um significado atribuído ao espaço tem em sua duração e permanência a possibilidade de cair num contexto de consensualidades e condutas recursivas, atribuindo-Ihes um sentido fundado essencialmente na realização cotidiana dessa existência. Essa dinâmica é que permite ao Ser ter sentido construído, atribuído e compartilhado no convívio cotidiano.

O sentido aqui assumido para fenomenologia funda-se em estudos de Martin Heidegger (2012, p.99) e considera que "na caracterização provisória do objeto temático da investigação (ser do ente ou sentido do ser em geral) seu método já foi também previamente delineado.". Não se trata, de modo algum, "nem de um ponto de vista, nem da subordinação a uma corrente, pois a fenomenologia não é nenhuma dessas coisas e jamais poderia sê-lo [...]." (HEIDEGGER, 2012, p.101). Já que se trata de um processo, do como e do modo de tratar um fenômeno.

Fenomenologia diz, então, fazer ver a partir dele mesmo o que se mostra tal como ele por si mesmo se mostra. Esse é o sentido formal da pesquisa que a si mesma se denomina de fenomenologia. [...] Fenomenologia não nomeia o objeto de suas pesquisas, nem caracteriza seu conteúdo-de-coisa. A palavra somente informa sobre o como do mostrar e o modo de tratar aquilo de que se deve tratar nessa ciência. (HEIDEGGER, 2012, 119).

Por isso a relevância do sentido de Ser; é por meio do fenômeno que o ser de um ente se revela, desta maneira "O termo 'fenomenologia' exprime uma máxima que pode ser assim formulada: às coisas elas mesmas!" (HEIDEGGER, 2012, p.101). Por isso as geograficidades. O ente humano pode ser assim traduzido, em seu sentido de Ser, visto que esse é fenômeno que nos liga íntima e profundamente à Terra. Essa compreensão corrobora com as reflexões de Schutz (2012) sobre a fenomenologia enquanto método ligado ao entendimento de nossas experiências do, e no mundo. Esse direcionamento filosófico e epistemológico propicia a compreensão de geograficidades alheias e suas influências em ações políticas e relações sociais cotidianas, em razão das geograficidades revelarem elementos do íntimo e do profundo nas relações e interações entre Ser, Terra e mundo vivido.

Ao admitir esses pressupostos, as correlações entre fenomenologia e ciência da cognição tornam-se substanciais, pois ambas se fundam, a partir de preceitos e caminhos distintos com aproximações e distanciamentos, na tentativa de compreensão do Ser e de suas experiências na realização de sua ontologia e existência. Seja em seu sentido (fenomenologia), ou seus fenômenos gerativos (ciência

$\begin{array}{llllll}\text { Caminhos de Geografia } & \text { Uberlândia - MG } & \text { v. 19, n. } 67 & \text { Set/2018 } & \text { p. 83-98 } & \text { Página } 85\end{array}$


da cognição), a existência que permite ao Ser autoatribuir e atribuir ao outro algum sentido, produz, com base em relações e interações cognitivas e nas experiências, fenômenos próprios do humano e que propiciam ao Ser assumir significados sempre imersos num mundo de ontologias e existências múltiplas.

A espacialidade do Dasein reside na mundidade do mundo circundante como o cotidiano mais próximo da existência de um ente e está imerso no sentido do seu Ser. Desta maneira, a dimensão espacial da existência assume significado e relevância para a vida humana a partir da determinação do Dasein como um modo de ser-no-espaço

A investigação da espacialidade do Dasein e da determinidade-espacial do mundo tem seu ponto-de-partida numa análise do utilizável do interior-do-mundo no espaço. A consideração passa por três graus: 1. a espacialidade do utilizável do-interior-domundo; 2. a espacialidade do ser-no-mundo; 3. a espacialidade do Dasein e o espaço. (HEIDEGGER, 2012, p.299).

Considera-se, portanto, que mundo carrega uma espacialidade e concretude intrínsecas, mas também duração e permanência, imaginário e memória. Por isso a substancialidade do sentido de Ser e das suas geograficidades intrínsecas. Tudo isso versa sobre os processos constitutivos do Dasein que formam e são formados na realização do ser-no-mundo, o que implica na consideração das experiências ontológicas e existenciais do ente humano.

$\mathrm{Na}$ dimensão espacial da existência as geograficidades nascem com esse mundo fenomenológico e existencial, e tem na Terra, que oferece a natureza circundante, a estabilidade para a existência humana. "A Terra é, por excelência, para o homem, como destino, a circunstância (circumstare), aquilo que se ergue à sua volta e mantém sua presença como engajamento no Ser." (DARDEL, 2011, p.43). Isso permite considerar que a atenção de Heidegger (2012) dedicada à compreensão e à explicação da mundidade desse mundo circundante repousa na relevância que a criação e o sentido fenomenológico atribuído ao mundo têm em relação ao sentido de ser-no-mundo. Sua existência se realiza dentro desse mundo criado por ele mesmo em sua coexistência cotidiana com outros.

O Dasein-com dos outros e o cotidiano ser-com [...] Outros que assim "vêm-deencontro" na conexão-instrumental utilizável do-mundo-ambiente, os quais não são como que acrescentados pelo pensamento a algo que de pronto só subsistisse, mas essas "coisas vêm-de-encontro a partir do mundo em que são utilizáveis para os outros, mundo que de antemão já é sempre também o meu. (HEIDEGGER, 2012, p.341-342).

A geografia, ao se preocupar com a dimensão espacial da existência, tem no mundo circundante a materialização e a concretude intrínsecas aos diferentes significados atribuídos ao espaço. Logo, as geograficidades permitem compreender a espacialidade inerente à vida cotidiana e conceber o sentido de Ser a partir do seu modo de ser e estar em relação ao espaço. A compreensão da existência humana, com vistas ao diálogo e à ação política, demanda da ciência da cognição o entendimento dos fenômenos gerativos do conhecer e do viver social e da fenomenologia, o entendimento da dinâmica relacional e interativa estabelecida entre o Ser e o mundo circundante do ser-no-mundo.

Isso justifica a importância atribuída por Pádua (2005), e corroborada aqui, ao espaço em suas reflexões sobre a fenomenologia em Martin Heidegger. A compreensão do fenômeno do mundo circundante sofre influências claras da dimensão espacial da existência, visto que Heidegger (2012) atribui espacialidade à realização da vida cotidiana baseado na evidência e concepção do ser-noespaço e ao mesmo tempo do ser-no-mundo traduzidos a partir do seu modo de Ser, estar e existir.

Para o esforço de compreensão de um sentido para o Ser e dos fenômenos da existência humana, dentre os quais possibilitam ao Ser adquirir sentido e ter-Ihe algum sentido atribuído, é essencial a forma como significamos o espaço. Tanto a espacialidade como as geograficidades são fenômenos que nos revelam modos de ser-e-estar-no-mundo. Essa dinâmica de encontros cria o convívio peculiar da coexistência de diferentes entes nesse mesmo mundo e a espacialidade inerente propicia a aproximação, e com isso a partilha de vivências e experiências.

O sentido de Ser e as geograficidades têm no fenômeno dos saberes suas essencialidades. Por isso, os saberes são admitidos como algo constituído através de processos subsidiados e alimentados pelas as atividades do espírito - pensar, querer e julgar - (ARENDT, 2000a; 2000b) e ao mesmo tempo intimamente relacionados à condição humana de existência; às experiências e vivências cotidianas. O fato de sermos seres vivos cognoscentes permite interpretações, entendimentos e explicações diversas a respeito dos fenômenos, processos e objetos cognoscíveis. Contudo,

$\begin{array}{llllll}\text { Caminhos de Geografia } & \text { Uberlândia - MG } & \text { v. 19, n. 67 } & \text { Set/2018 } & \text { p. 83-98 } & \text { Página } 86\end{array}$


"Tendemos a viver num mundo de certezas, de solidez perceptiva não contestada, em que nossas convicções provam que as coisas são somente como as vemos e não existe alternativa para aquilo que nos parece certo." (MATURANA e VARELA, 2001, p.22). A partir dessa citação gostaria de iniciar uma reflexão para além das questões biológicas implícitas e explícitas na frase e entrar em questões epistemológicas sobre os critérios de aceitabilidade para aquilo considerado por nós cientistas, conhecimento válido e, sobretudo o que é constitutivo do humano no ato de conhecer.

É importante ressaltar, com base nesse entendimento, a consideração da realidade como fenômeno oriundo das experiências construídas por meio de relações e interações cognitivas entre Ser e mundo. A realidade apresenta-se como um fenômeno intimamente ligado ao observador e não um ente independente existente por si só e em si mesma. As proposições explicativas sobre essa realidade intersubjetiva são sempre uma experiência de distinção realizada por um observador, que distinguem experiências ocorridas com ele mesmo ou em relação a ele mesmo (MATURANA, 1997). É assim para todo e qualquer tipo de proposição explicativa.

Então uma explicação envolve, implícita ou explicitamente, a aceitação de que aquilo que se explica é resultado de um mecanismo ou processo gerativo que, de fato, específica tanto sua natureza, como a aplicação, pelo observador, de algum critério de aceitação que o observador inclui em seu escutar para aceitar ou rejeitar o mecanismo ou processo gerativo proposto. (MATURANA, 1997, p.213).

A somatória de explicações sobre experiências que permitem distinguir experiências em mim e no outro cria um contexto mais amplo de propostas explicativas relacionando fenômenos entre si, com o consequente e contínuo aprofundamento e complexificação das explicações e do que se aceita como explicação; daí a compreensão dos fenômenos, das experiências e o surgimento dos saberes.

Ao considerar a cognição e a experiência fenômenos constitutivos do humano, considera-se haver interfaces entre ambos e um jogo recíproco de influências quando se trata dos processos de construção de saberes. A intenção aqui não é separá-los para identificar as características intrínsecas de cada um, mas considerá-los enquanto fenômenos processuais como um continuum, essenciais ao ato de conhecer e aos processos criativos humanos. As relações e interações cognitivas e as experiências não nos remetem apenas ao universo mensurável. Nessa perspectiva, Schutz (2012) explica a experiência como um fluxo de consciência;

Aquilo que nós de fato experienciamos na duração não é um ser que é discreto e bem definido, mas uma constante transição de um aqui e agora para um novo aqui e agora. [...] o "Agora" é uma fase, mais do que um ponto, de modo que as diferentes fases se fundem umas com as outras ao longo de um continuum." (SCHUTZ, 2012, p.72-73 e 75).

O conhecer e as proposições explicativas que o compõem têm nas atividades do espírito e na experiência seus instrumentos constitutivos, os quais são alimentados pela imaginação e pela memória, ao possibilitar sua materialização por meio da linguagem. É, portanto, "[...] um fenômeno do operar do ser vivo em congruência com sua circunstância [...]" (MATURANA, 2001, p.34), ao observar estamos então imersos num fenômeno cognitivo de relações e interações também cognitivas.

Essas relações e interações vividas por meio das experiências criam nossas realidades. "[...] minha afirmação cognitiva é válida pelas coerências operacionais que a constituem. " (MATURANA, 2001, p.36). Com isso, a validade do que digo sobre minhas experiências não depende de ela ser realizada dentro dos preceitos científicos, mas sim de ser coerente para quem a escuta. Quando faço a pergunta pelo observador, a realidade passa a ser uma proposição explicativa, "[...] a realidade é sempre um argumento explicativo. " (MATURANA, 2001, p.38).

São as interações recorrentes que propiciam o acumulo de proposições explicativas e a partir disso a compreensão dos fenômenos, processos e objetos se realiza (MATURANA, 1997; 1998). Unem-se aqui duas compreensões sobre cognição e vida cotidiana (SCHUTZ, 2012 e MATURANA, 2001), correlacionando-as com a experiência vivida de ser-no-mundo.

Ao evidenciar a interação entre imaginário, memória e saberes, evidencia-se também a linguagem enquanto fenômeno humano do comunicar e do compartilhar o universo cognitivo. A experiência de viver na linguagem e, por meio dela apresentar e representar pensamentos, sentimentos e reflexões, é o fenômeno que possibilita os saberes.

Por meio da linguagem o imaginário e as atividades do espírito se manifestam para além do íntimo de cada um. Isso ocorre também com o pensamento reflexivo contido nas ciências; não há pensamento reflexivo sem representação imaginária (CASTORIADIS, 2004). Para não reduzir o imaginário e a

$\begin{array}{llllll}\text { Caminhos de Geografia } & \text { Uberlândia - MG } & \text { v. 19, n. } 67 & \text { Set/2018 } & \text { p. 83-98 } & \text { Página } 87\end{array}$


memória a faculdades da mente, têm-se nesses dois processos internos do ser humano fatores essenciais à cognição e às suas possíveis criações, especificamente, os saberes.

[...] a imaginação criadora desempenha um papel fundamental tanto na ciência quanto na filosofia. Toda grande obra filosófica é uma criação imaginária, [...] o mesmo acontece em ciência. Os grandes avanços científicos procedem da criação de novos esquemas imaginários, que são formados sob a pressão da experiência disponível, mas não "decorrem" dessa experiência. (CASTORIADIS, 2004, p.138).

Houve um forte e evidente privilégio durante o século XIX no pensamento geográfico dado ao tempo em detrimento ao espaço. A Geografia nasce, enquanto ciência, num período no qual a dimensão espacial dos fenômenos e objetos não reinava nas ciências sociais e humanas. Dentre os vários e diferentes autores da Geografia, que tratam a respeito desses temas, tem-se Soja (1993) e Philo (1996) que destacam tais características e expõem de maneira bastante detalhada os processos teóricos e embates filosóficos realizados para a sua parcial superação na Geografia e como a noção de espaço passou a ser essencial ao entendimento do presente geográfico.

Ao desconsiderar o espaço como um fenômeno traduzido e entendido apenas a partir da listagem de fatos históricos, "[...] geralmente cadeias de causas-e-efeitos que se perseguem 'através dos anos' [...]" (PHILO, 1996, p.271), a questão temporal ganha outra dimensão e sua análise não se restringe à linearidade dos fatos e sim às ações que ali ocorreram e ainda ocorrem no presente da coexistência humana. Nas ciências em geral e na Geografia em particular, os saberes do passado ainda alimentam a construção dos saberes do presente. A complexidade da vida cotidiana não encontra mais abrigo em argumentos que a noção de linearidade condiciona a compreensão dos fenômenos e processos. Paul Claval (2002) faz uma crítica em relação a tal noção, afirmando ser características de heranças naturalistas e funcionalistas de entendimento das ciências.

O entendimento sobre o fenômeno do espaço e as causas e desdobramentos de sua organização e produção na vida cotidiana, tem nas resultantes oriundas da política a expressão de relações sociais que precisam ser consideradas nas análises. A dialética sócio-espacial colocada por Soja (1993) implica na investigação das contradições próprias do sistema capitalista de produção. A estrutura do espaço organizado estabelece, portanto, uma correlação reciproca e "[...] dialeticamente definido de relações e produções gerais, relações estas que são simultaneamente sociais e espaciais." (SOJA, 1993, p.99).

Essa dialética considerada a partir do materialismo histórico abre a possibilidade da análise sistêmica no pensamento geográfico, e ao mesmo tempo propor uma análise para a vida cotidiana dentro de um contexto mais complexo de relações e interações quando comparado com o que era desenhado anteriormente. Essa complexidade que começa a adquirir destaque nas ciências humanas é providencial à política dentro do pensamento geográfico. Quando Claval (2002) admite que havia uma Geografia Humana que falava pouco de seres humanos, essas alterações epistemológicas e filosóficas, iniciadas entre 1970 e 1980, permitiram uma construção teórica que evidencia o fundamento e o sentido geográfico intrínseco à política. Ora, se a geografia distancia seus argumentos e proposições explicativas da vida cotidiana, traduzida nas espacialidades e geograficidades que a caracteriza, define e encerra, sua compreensão sobre política elimina o essencial do fenômeno: o Ser do ente que a promove e a materializa nas relações e interações sociais cotidianas.

A década de 1970 e 1980, mais precisamente a de 80, marcaram simbolicamente uma retomada do debate sobre a questão do espaço na teorização da Geografia. Houve uma afirmação e predileção teórica "[...] de um materialismo histórico profundamente espacializado." (SOJA, 1993, p.58). A inclusão da dimensão espacial na teorização social crítica proposta pela Geografia exigiu uma desconstrução e uma reconstituição teóricas num universo bem estabelecido de teorias. É importante destacar a separação entre as proposições explicativas de elucidação do fenômeno do espaço e sua conceitualização das explicações sobre a organização do espaço, sendo este, produto da vida social. Em ambos os casos, o espaço é colocado como base e dado contextual da espacialidade dessa vida social.

O espaço, nessa forma física generalizada e abstrata, foi conceitualmente incorporado na análise materialista da história e da sociedade, a ponto de interferir na interpretação da organização espacial humana como um produto social, passo primeiro e fundamental para se reconhecer uma dialética sócio-espacial. [...] Mas esse espaço físico foi uma base epistemológica ilusória para se analisar o sentido concreto e subjetivo da espacialidade humana. O espaço em si pode ser 
primordialmente dado, mas a organização e o sentido do espaço são produto da translação, da transformação e da experiência sociais. (SOJA, 1993, p.101).

Por isso a substituição da noção de meio por espaço geográfico (CLAVAL, 2002) foi uma das principais questões da abertura do pensamento geográfico, ao considerar a concepção sistêmica para a compreensão da teoria social crítica. Ao perceber o papel que cumpria as relações e as interações entre os lugares, as redes sociais e econômicas formadas, considerando que "As cidades são comutadores sociais, formas de organizações do espaço destinadas a facilitar ao máximo todas as formas de interação." (CLAVAL, 2002, p.18), e a política, como um fenômeno central na organização e produção do espaço, o pensamento geográfico passa a admitir e a investigar em outras perspectivas teóricas e epistemológicas as correlações da política com a dimensão espacial da vida cotidiana, e a partir disso compreender seu fundamento e sentido geográfico. Ao considerar que a vida cotidiana possui uma dimensão espacial que the é peculiar, considera-se que todos os fenômenos e processos por ela acolhidos, dentre os quais encontra-se a política, também possuam tais características.

No caso da Geografia e do espaço fenomênico, nas três últimas décadas há transformações intensificadas, tanto na dinâmica da vida social e política, como na epistemologia das ciências, que inevitavelmente alcançaram a Geografia e a maneira como explicamos o fenômeno do espaço. A citação acima refere-se a um período destacado por Soja (1993) e Philo (1996) como de grande efervescência científica e filosófica e, portanto, de profundas alterações epistemológicas nas ciências. Esse período se repete, e o destaque adquirido e atribuído às teorias quânticas, fenomenológicas e à física do não-equilíbrio, junto aos avanços da neurociência e da Ciência da Cognição têm provocado alterações bastante significativas na maneira de fazer ciência e no significado dessa ciência que é feita.

Entende-se que quando essa transformação é parcial e fragmentária fenômenos, objetos e processos continuam sendo analisados, ora com os novos paradigmas epistemológicos disponíveis, ora com fundamentos de uma construção teórica já ultrapassada (SANTOS, 2008). Nessa trama, muitas vezes criam-se obstáculos puramente ideológicos interferindo na continuidade de um processo de transformações imprescindíveis os quais podem beneficiar os usos possíveis para os saberes construídos.

O geógrafo alemão Benno Werlen (2012), no final da década de 1980, apresenta uma teorização para a Geografia que altera seu tratamento da teoria social,

Essa abordagem não procurou explicar ações individuais e práticas sociais em termos de aspectos geográficos, como a distância e o clima, mas praticamente o oposto, explicar fenômenos geográficos em termos de ações e práticas sociais. (WERLEN, 2012, p.550).

No pensar sobre o espaço e seus significantes e significados, a ação humana, com suas práticas sociais e políticas, passa a ser constitutiva desse espaço e de sua organização. Destaca-se o papel central do agente-sujeito político dessa ação, como disse Werlen (2012, p.552) "Na minha perspectiva, o sujeito não pode ser entendido como dominado ou determinado por circunstâncias objetivas.". Muito embora o contexto material influencie nossas ações, ele não as determina, pois isso reduziria as nossas ações a relações de causalidades entre o ente humano e um objeto técnico. Essa perspectiva é as vezes explicitada pelo materialismo histórico nas teorias geográficas. O próprio Milton Santos (2008) define a compreensão e a explicação do espaço geográfico fundado no entendimento das inter-relações existentes entre sistemas de objetos e sistemas de ações.

Para os geógrafos, os objetos são tudo o que existe na superfície da Terra, toda herança da história natural e todo resultado da ação humana que se objetivou. Os objetos são esse extenso, essa objetividade, isso que se cria fora do homem e se torna instrumento material de sua vida, em ambos os casos uma exterioridade. (SANTOS, 2008, p.72-73).

Embora a ação seja a única atividade da condição humana que ocorra entre agentes-sujeitos independentemente da materialidade circundante (ARENDT, 2014), quando ela pretende-se política, e com isso resultar em intervenções na vida social cotidiana, os objetos técnicos e nossas relações e interações para com eles passam a ser essenciais. Talvez isso tenha levado Santos (2008) a fazer ressalvas ao falar sobre o espaço como um híbrido e a colocar a intencionalidade entre a ação e o objeto: se o espaço geográfico é significado atribuído, então ele nasce de ações realizadas e relações e interações construídas e estabelecidas. 


\begin{abstract}
Esses objetos não têm por si mesmos uma história, nem uma geografia. Tomadas isoladamente em sua realidade corpórea, aparecem como portadores de diversas histórias individuais, a começar pela história de sua produção intelectual, fruto da imaginação científica do laboratório ou da imaginação intuitiva da experiência. Mas sua existência histórica depende de sua inserção numa série de eventos - uma ordem vertical - e sua existência geográfica é dada pelas relações sociais a que o objeto se subordina, e que determinam as relações técnicas ou de vizinhança mantidas com outros objetos - uma ordem horizontal. Sua significação é sempre relativa. (SANTOS, 2008, P.102).
\end{abstract}

Essa perspectiva começa a abrir outras possibilidades de proposições explicativas centradas na dimensão e interações espaciais da vida social e política. Ao fazê-lo, abre-se também a possibilidade para outra noção de política espacial (MASSEY, 2004; 2013), centrada, sobretudo nas geograficidades. Essa constante transformação teórica e epistemológica permite pensar sobre o fenômeno do espaço a partir da essencialidade da ação. No entanto, o pensamento geográfico científico não possui consensualidade sobre tal aspecto do pensar sobre o espaço. Nesse sentido, há um destaque direcionado para pensamentos e pensadores ligados a teorias científicas e filosóficas com coerências epistemológica e reflexiva para um diálogo, pois como admite que a consciência e a sensibilidade geográficas surgem da, e na experiência espacial, a ação é o fenômeno essencial no processo de constituição de geograficidades advindas da ontologia existencial resultante das relações e interações cognitivas no cotidiano.

A consciência e a sensibilidade geográficas são reveladas por meio de ações e práticas sociais e políticas com dimensões e interações espaciais clarividentes. Proposições explicativas sobre a experiência vivida em sua dimensão espacial compõem saberes que povoam a mente e nutrem as ações humanas muito antes do surgimento, a rigor, das disciplinas científicas. Destaca-se, todavia, a relevância do pressuposto citado antes, o qual entende as criações humanas, sobretudo os saberes, como produtos de relações e interações cognitivas com o mundo e não algo possível apenas por meio do método científico; saberes não são aprendidos, são construídos. Tudo isso

Trata-se menos de períodos cronológicos do que de atitudes duráveis do espírito humano frente a frente com a realidade circundante e cotidiana, em correlação com as formas dominantes da sensibilidade, do pensamento e da crença de uma época ou de uma civilização. (DARDEL, 2011, p.47).

Entende-se que esse conjunto de correlações ao qual Dardel (2011) se referiu aparece e se evidencia especialmente na dimensão espacial da vida humana. Nesse emaranhado de proposições explicativas sobre tal tema, a Geografia se destaca por ter em sua concepção e ser, portanto, uma espécie de ente constitutivo, o espaço geográfico como sua preocupação essencial. A Geografia se realiza ao trazer proposições explicativas sempre ligadas à dimensão e às interações espaciais enquanto meio e fim em suas criações teóricas e epistemológicas.

As reflexões sobre a ação política e suas correlações com o espaço justifica-se pela compreensão dos sentidos e fundamento geográficos dessa ação. Considera-se que as geograficidades atribuem sentido geográfico à ação e o espaço lhe garante seu fundamento. Isso direciona ao sentido da ação política uma significativa base geográfica e a liga íntima e profundamente com a dimensão espacial da coexistência humana, seus saberes e fazeres de ser-no-mundo e ser-no-espaço.

\title{
OS SENTIDOS E O FUNDAMENTO GEOGRÁFICO DA AÇÃO POLÍTICA
}

Para a continuidade e aprofundamento no debate sobre como a Geografia pensa (ou pode pensar) a dimensão espacial da existência e sua interface com a ação política, retomam-se as reflexões iniciais sobre as condições humanas de ser-e-estar-no-e-com-o-mundo. Tem-se agora a inclusão nas reflexões sobre as questões de Ser, a análise de fenômenos envolvidos nas atividades do espírito pensar (cognitivo), querer (a vontade) e julgar (liberdade política) - e que precedem a ação política.

É importante destacar que a liberdade no campo da política não é um fenômeno nascido a partir da vontade da simplesmente (ARENDT, 2007). Caso assim o fosse, voltaríamos à noção da filosofia cristã para liberum arbitrium, ou seja, a liberdade de escolha entre duas opções dadas. Ao contrário, a liberdade na política reside na perene possibilidade "[...] de chamar a existência o que antes não existia, o que não foi dado nem mesmo com um objeto da cognição ou de imaginação [...]" (ARENDT, 2007, p.198). É por isso, e baseado nisso, que a ação política e o viver social precisam coexistir, sobretudo quando há necessidade de transformações sociais profundas as quais demandam

$\begin{array}{llllll}\text { Caminhos de Geografia } & \text { Uberlândia - MG } & \text { v. 19, n. } 67 & \text { Set/2018 } & \text { p. 83-98 } & \text { Página } 90\end{array}$


liberdade para pensar, querer e julgar sobre coisas e relações ainda inexistentes; é a possibilidade de sempre começar algo novo.

Os saberes, ao propiciar a ação, a intervenção e a transformação têm como precedentes o pensar cognitivo, constituído na atividade do conversar comigo mesmo e numa perspectiva reflexiva para num segundo momento transformar-se em diálogo com o outro. O querer, ligado ao fenômeno da vontade e nascido da atividade do pensar, nos colocando a agir, e o julgar, onde reside a escolha de como agir, que nos permite a prática da liberdade política para fazer surgir o até então inexistente, possibilidade inerente à ação. (ARENDT, 1993; 2000a; 2000b).

Como a preocupação centra-se nos fenômenos da ação e da experiência, condições sine quibus non para dar sentido e fundamentar nosso universo de significantes e significados, é essencial refletir sobre a perspectiva espacial intrínseca à existência. Tanto a ação como a experiência revelam o quão significativa é a dimensão espacial da vida social cotidiana. Esse ponto cria também uma interrelação com as reflexões anteriores sobre os processos de relações cognitivas com o mundo, visto que tais fenômenos - ação e experiência - possuem íntima relação com a realização do Dasein e o sentido de Ser, e consequentemente com o pensar sobre o espaço, a partir dos processos sociais e políticos constituintes de seus significados possíveis.

Segundo essa trama de relações entre seres humanos viabilizam-se as condições sine qua non para os saberes e os fazeres. É no cotidiano onde caracterizamo-nos diante do mundo vivido. Nessa ótica, a geograficidade é compreendida como o fenômeno das relações concretas que liga o ser humano à Terra (DARDEL, 2011) e ainda traduz e caracteriza os domínios de existência (MATURANA, 1997; 2001). Admite-se a realização do humano, dependente e através de uma interioridade, mas, sobretudo, numa dinâmica relacional (MATURANA, 1997) com o mundo, com os outros seres vivos e com outros seres humanos.

A dinâmica biológica do ser vivo - que também chamo sua fisiologia -, na medida em que realiza o ser vivo, resulta na constituição desse como totalidade, que tem um domínio de relação que um observador vê como seu domínio de conduta ou modo de vida. [...] A fisiologia dá origem, faz possível e limita a vida de relação de um ser vivo, mas não a determina, causa ou contém. (MATURANA, 1997, p.109).

Essa ressalva colocada por Maturana (1997) em relação à fisiologia é importante, pois como há reflexões a respeito das atividades do espírito precedendo à ação, seria contraditório falar em ação e liberdade políticas (ARENDT, 1993; 2000b; 2014) e ao mesmo falar em determinismo fisiológico para a condição humana. Outro ponto relevante é a frequente confusão entre o entendimento das condições fisiológicas que constituem o ser humano enquanto sistema vivo e as condições de desenvolvimento do Ser ontológico existencial por meio das experiências e vivências cotidianas.

Enquanto sistemas vivos, existimos em dois domínios fenomênicos que não se intersectam: o domínio de nossa realização em nossa corporalidade (o domínio da fisiologia), e o domínio de nossas interações como totalidades (o domínio do comportamento). Apesar desses dois domínios não se intersectarem, eles são acoplados em sua realização através do modo de operação do sistema vivo enquanto uma entidade determinada estruturalmente. (MATURANA, 1997, p.299).

Os interesses aqui são pelos estudos do Ser e da aparência; o domínio do comportamento e da realização do Dasein na existência cotidiana. Por esse motivo o espaço relacional faz-se essencial nessa reflexão. A ação política e as geograficidades, ao dar sentido para a realidade espacial, ocorrem na e pela pluralidade intrínseca à coexistência humana. A fisiologia da espécie não é vista aqui enquanto fator determinante, mas simplesmente como características que exprimem conjuntos de possibilidades ilimitadas para a experiência ontológica existencial, o agir político e a construção de saberes.

Ao compreender que as ações humanas, quando políticas, somente são possíveis no convívio coletivo, é necessário estabelecer estratégias para fazer desse convívio coletivo conditio sine qua non para o viver social ali instituído. Nesse contexto, todos os viveres sociais instituídos, ao possuírem sua própria dinâmica de relações e interatividades entre os agentes-sujeitos de sua composição, precisam, para manter o sentido de sistema social, da cumplicidade espontânea com dupla funcionalidade: gerativa e conservadora de relações, interações e significados que dão sentidos à vida social.

Os sistemas sociais instituídos, denominados aqui de vida social ou viver social, realizam-se por meio das interações recorrentes ao formar uma rede de ações coordenadas (MATURANA, 1997), produtos e produtoras dessa organização a qual pode ser identificada e caracterizada como sendo um sistema

$\begin{array}{llllll}\text { Caminhos de Geografia } & \text { Uberlândia - MG } & \text { v. 19, n. 67 } & \text { Set/2018 } & \text { p. 83-98 } & \text { Página } 91\end{array}$


social. Qualquer mudança no viver social somente é possível quando essa rede de ações coordenadas, através dos agentes-sujeitos que a compõem, também sofre alguma transformação. Isso pode ser motivado, por exemplo, por uma ação política ao incluir novos comportamentos e novos significados a essas interações recorrentes e relacionais do cotidiano.

Essa dinâmica faz da linguagem fenômeno essencial aos processos que a compõem, pois a linguagem somada à ação forma elementos fundamentais para a realização da vida social (MATURANA, 1997 e ARENDT, 2014). Como atividade da condição humana de existência e do exercício político do agir em concerto, sem o desenvolvimento da linguagem não desenvolveríamos a ação. Portanto, a linguagem e a compreensão das atividades do espírito trouxeram à consciência humana a compreensão de fenômenos internos gerativos dessas atividades, sem os quais nós não nos realizaríamos enquanto seres sociais.

Isso justifica a linguagem imersa na dialogicidade; a linguagem e o diálogo são essenciais para o eu pensante alcançar o pensamento alheio. Ao entender o diálogo como um ato de criação coletiva (FREIRE, 2005), este se faz essencial ao pensar cognitivo com vistas à ação. Nessa coexistência cotidiana com o outro, a exposição do pensar por meio da linguagem revela um eu interior construído pelas e nas experiências e ao mesmo tempo adquire consciência a partir das atividades do espírito, justificando a relevância essencial da experiência.

O significado etimológico da palavra dialogo "[...] vem do grego diálogos. Logos significa 'palavra' ou, em nosso caso, poderíamos dizer 'significado da palavra', e dia significa 'através' - e não 'dois', como parece." (BOHM, 2005, p.33-34). Assim, a etimologia da palavra sugere um conjunto de significados que fluem entre, e através de quem do diálogo participa. A partir do fluir de significados inerentes ao diálogo também podem surgir compreensões novas sobre fenômenos, processos e/ou relações.

O retrato ou imagem sugerido por essa derivação é o de uma corrente de significados que flui entre nós e por nosso intermédio; que nos atravessa, enfim. Esse fato tornará possível o fluxo de significados na totalidade do grupo, e daí podem emergir compreensões novas. Trata-se de algo inédito, que pode não estar presente no ponto de partida. Esse significado compartilhado é a "cola", ou "amálgama" que mantém juntas as pessoas e as sociedades. (BOHM, 2005, p.34).

Ao questionar o que nos faz pensar, Arendt (2000a) diz ser uma necessidade coeva à existência humana na Terra e "[...] não inquire de causas nem de finalidades." (ARENDT, 2000a, p.147). Contudo, o cotidiano criou inúmeras finalidades ao pensar, sobretudo, ao pensar cognitivo que conduz as atividades do espírito e permite identificar, a partir de um querer e fundamentado na liberdade do julgar, caminhos para construir diferentes domínios cognitivos experienciais e contextos de organização do tecido social e do corpo político.

Nos estudos de Arendt (2000a; 2000b) a atividade mental de julgar aparece por excelência como a mais política delas, pois se considera o julgar "[...] o produto derivado do efeito libertador do pensar, realiza o pensar, torna-o manifesto no mundo das aparências [...]" (ARENDT, 2000a, p.212). O exercício do julgar é sempre alimentado pelas outras atividades do espírito, pensar e querer, e ao mesmo tempo influenciado pelo íntimo e profundo, evidenciados nas geograficidades construídas no cotidiano.

O fenômeno da ação é uma atividade intrínseca à condição humana, e as atividades do espírito intrínsecas à ação. Isso atribui à ação política uma responsabilidade substancial para os desdobramentos no cotidiano das pessoas. "[...] os princípios segundo os quais agimos e os critérios segundo os quais ajuizamos e conduzimos as nossas vidas dependem em última instância da vida do espírito." (ARENDT, 2000a, p.83). Assim, na vida do espírito (e suas atividades inerentes) o pensar não pode ser alimentado para um querer que não julga, mas subjuga as pessoas e seus viveres e sentires sociais. A liberdade política requerida pela ação precisa manifestar-se nas relações e interações espaciais que compõem e dão sentido ao cotidiano.

A busca pela aquiescência na ação política passa inevitavelmente pelo diálogo entre os agentessujeitos participantes do processo de agir. Por isso, as questões do Ser e da aparência surgem com tamanha relevância. Como na ação o agente-sujeito se revela ao agir; essa revelação é apresentada por meio da aparência, ao revelar seu ser. Logo, a aparência sempre será um parece-me e o Ser sempre é ao mesmo tempo aparência para o outro Ser, que também me é um parece-me (AREDNT, 2000a). Todos nós aparecemos uns aos outros e somos uns para os outros. 
Estar vivo significa estar possuído de um impulso de automostração que responde ao fato da nossa dimensão de aparência. [...] Aparecer significa sempre parecer a outros, e este parecer varia de acordo com o ponto de observação e a perspectiva dos espetadores. [...] Parecer corresponde ao facto que todas as aparências, a despeito da sua identidade, são percebidas por uma pluralidade de espetadores. (ARENDT, 2000a, p.31-32).

Ao falar sobre ação política é imprescindível falar também sobre onde ela se realiza. A espacialidade intrínseca ao Dasein faz do Ser necessariamente um estar. Como a ação é uma das atividades fundamentais da vida humana, ela possui na sua realidade intersubjetiva uma dimensão espacial inerente à sua realização. Arendt (2014) denomina de espaço da aparência, visto que é na ação que os agentes-sujeitos se revelam e tal revelação ocorre no processo de aparecer através da dimensão e das interações realizadas na espacialidade da coexistência cotidiana.

Como homo sapiens somos uma única espécie, no entanto enquanto seres humanos somos distintos uns dos outros - nossa pluralidade - e essa distinção é partilhada com todos os outros seres vivos e entre nós mesmos.

Se não fossem iguais, os homens não poderiam compreender uns aos outros e os que vieram antes deles, nem fazer planos para o futuro, nem prever as necessidades daqueles que virão depois deles. Se não fossem distintos, sendo cada ser humano distinto de qualquer outro que é, foi ou será, não precisariam do discurso nem da ação para se fazerem compreender. Sinais e sons seriam suficientes para a comunicação imediata de necessidades e carências idênticas. (ARENDT, 2014, p.220).

A partir disso a questão ontológica existencial torna-se substancial, pois ela propicia ao agente-sujeito assumir e evidenciar o sentido do seu Ser na ação. Nesse caso, somente o diálogo poderia dar abrigo a essa pluralidade sem a tentativa de negá-la. A dialogicidade possui duas dimensões solidárias, a ação e a reflexão (FREIRE, 2005). Esses fenômenos devem compor o antes e o durante da ação política.

Para Paulo Freire (2005) o diálogo é ele mesmo a palavra; decorre-se que não é no silêncio que o humano se realiza. Desta maneira, o pensar cognitivo torna-se comunicável também por meio das palavras (ARENDT, 2000a). "Existir, humanamente, é pronunciar o mundo, é modificá-lo. O mundo pronunciado, por sua vez, se volta problematizado aos sujeitos pronunciantes, a exigir deles novo pronunciar." (FREIRE, 2005, p.90). Invocam-se, portanto, as necessidades filosófica e conceitual de admitir os agentes-sujeitos como ao mesmo tempo "homens" de pensamento e "homens" de ação, pois, ação sem reflexão pode se transformar num fazer não reflexivo e que, portanto, ignora as atividades do espírito e a eterna possibilidade do novo. Isso impõe o risco de reduzir a ação a um simples fazer técnico, tal qual a fabricação de um objeto.

É necessário afastar da política essa lógica dos meios e dos fins para pensar na perspectiva do estabelecimento de princípios. Ao fazer restrições a certos meios para se alcançar determinados fins e considerar que, a depender do fim, os meios são justificáveis (ARENDT, 2014), corre-se o risco de admitir situações desfavoráveis à coexistência da pluralidade humana e consequentemente, ao viver social. "Enquanto acreditarmos que lidamos com fins e meios no domínio político, não poderemos impedir que alguém recorra a todos os meios para alcançar fins reconhecidos." (ARENDT, 2014, p.286). A degradação da política se espalha em nosso viver social e coloca sua essencialidade à vida coletiva em questão, visto que a noção de princípios para o agir político é substituída pela utilidade para a fabricação de algo, sendo transferido também para a "fabricação" de um modelo de produtividade e "progresso" da sociedade.

A própria ideia de ação, enquanto experiência humana realizando-se na coexistência da pluralidade dá suporte para considerá-la na perspectiva de processos relacionais de interações no cotidiano. Ao contrário da fabricação de algum objeto, o qual possui perecibilidade matematicamente calculável, a força da ação frente aos processos por ela desencadeados é ilimitada, pois, "[...] a ação não tem fim. O processo de um único ato pode perdurar, literalmente, por todos os tempos até que a própria humanidade tenha chegado a um fim." (ARENDT, 2014, p.291). Enquanto processo, a ação política nos sugere a necessidade da permanência de características e elementos propiciadores de seu desencadeamento e de sua íntima relação com o viver social. Isso torna imprescindível uma organização do tecido social voltada aos princípios (diálogo, autonomia, partilha) que regem as ações políticas desenvolvidas num determinado espaço geográfico. 
Ao admitir a ação como um fenômeno baseado na pluralidade humana e que, portanto, trata da convivência entre diferentes, admite-se o agir em concerto como sendo próprio da política, assim a ação aqui é essencialmente política.

A política surge no entre-os-homens; portanto, totalmente fora dos homens. Por conseguinte, não existe nenhuma substância política original. A política surge no intra-espaço e se estabelece como relação. (ARENDT, 2007, p.23).

Como o viver social baseia-se nas relações interativas das pessoas, os sistemas sociais são formados "[...] por seres vivos que, através de suas interações recorrentes, constituem uma rede de ações coordenadas na qual eles se realizam a si próprios como tais [...]" (MATURANA, 1997, p.189). Observa-se que tanto a ação como o viver social são fenômenos da vida cotidiana e ocorrem no espaço relacional das pessoas. Como os saberes, a política aparece-nos como um constructo social possível somente a partir desse espaço relacional e de suas interatividades recursivas do viver.

Ao passo que na ação política o novo é uma eterna possibilidade, no viver social ocorre o mesmo, "O devir histórico de qualquer sociedade é sempre o resultado desses dois processos: conservação e variação." (MATURANA, 1997, p.201). Transformações em viveres sociais são sempre possíveis, isso justifica a essencialidade da política para a vida social.

Ao longo da história nós encontramos inúmeros significados e explicações filosóficas e científicas atribuídas à política, no entanto o que está no seu âmago desde a polis grega é o fato de ocorrer a partir da, e na pluralidade humana. Contudo, dentre as diferentes explicações, surgiram preconceitos ligados ao seu exercício e à sua compreensão. Há nos dias atuais um entendimento fortemente influenciado pelas práticas dos políticos profissionais partidários, responsáveis por parte fundamental da gestão pública na democracia representativa do Estado brasileiro. Isso tudo motiva um crescente descrédito para com a política e acaba por nos afastar de assuntos considerados essencialmente humanos.

Para o viver social, a ação política precisa ser regida por meio de princípios para direcionar os meios e os fins necessários às transformações positivas e coletivas. Quando Maturana (1997) coloca o social como constituinte do ser humano, observa-se que o significado de ser humano aparece no viver social. O viver social é a experiência da partilha, o que torna relevante o apontamento da ação política e das atividades do espírito como intimamente ligadas ao diálogo e a cumplicidade entre os agentes-sujeitos participantes.

A conduta social está fundada na cooperação, não na competição. A competição é constitutivamente anti-social porque, como fenômeno, consiste na negação do outro. Não existe a "competição sadia" porque a negação do outro implica a negação de si mesmo ao pretender que se valide o que se nega. A competição é contrária à seriedade na ação, pois aquele que compete não vive naquilo que faz, aliena-se na negação do outro. (MATURANA, 1997, p.206).

Justifica-se, assim, a essencialidade da cooperação para o viver social que se nutre da, e nutri a ação política. "[...] a natureza íntima do fenômeno social humano está na aceitação e no respeito pelo outro [...]" (MATURANA, 1997, p.208-209). Nesse ponto, o exercício do pensar cognitivo pode ser direcionado a um querer que julgue a ação política a partir de princípios com vistas a construir cotidianamente um viver social, fundado na dialogicidade, na autonomia e na partilha. Isso justifica o sentido da política centrar-se na interação entre seres humanos em liberdade. Sem liberdade para as atividades do espírito, a ação corre o risco de se transformar em um simples fazer e o viver social não passar de processos de doutrinação para comportamentos institucionalmente legítimos.

Minha abordagem de uma teoria da ação enfatiza que as pessoas podem se desacorrentar e fazer as coisas diferentemente do modo como eram feitas antes. Em outras palavras as pessoas sempre possuem alternativas. Embora, circunstâncias materiais possam influenciar suas ações, certamente não as explicam. Isso significa, estritamente, que não há ligação causal entre "espaço" geográfico e ação; ações e práticas sociais não podem ser explicadas pelo espaço geográfico no sentido de uma explicação causal das ciências naturais. (WERLEN, 2012, p.552).

O não alheamento da ação em relação ao viver social é necessário, pois a política, enquanto fenômeno que induz o convívio da pluralidade inerente à nossa existência é condição humana para propiciar a instituição da vida social. A própria Hannah Arendt (1993) em escritos realizados entre os anos de 1946 e 1975 reconheceu fatos históricos ocorridos na vida social europeia como motivação do interesse pelas filosofias políticas. 
[...] o interesse atual pela política na Europa pode ser retraçado a partir de experiências políticas perturbadoras, em particular das duas guerras mundiais, dos regimes totalitários e da assustadora perspectiva da guerra total. [...]A repugnância frente a uma existência absurda desaparece quando o homem descobre que ele próprio não é dado a si mesmo, mas que pelo engajamento pode tornar-se quem escolheu ser. A liberdade humana significa que o homem cria a si mesmo em um oceano de possibilidades caóticas. (ARENDT, 1993, p.75 e 82).

Essa cumplicidade entre ambos - vida social e ação política - evidencia-se no espaço da aparência (ARENDT, 2014) e por meio das geograficidades, as quais se realizam e adquirem sentido no espaço geográfico; o espaço do vivido, das experiências e do cotidiano. Partindo do pressuposto de que a separação existente na polis grega entre vida pública e vida privada se desfez ao longo da história social humana, há atualmente uma evidente inter-relação entre política e viver social nos espaços da aparência e no geográfico. É através deles e fundamentado neles que se realizam e adquirem sentido esses dois fenômenos da vida humana.

As reflexões de Doreen Massey (2013) chamam a atenção para implicações que o sentido do espaço traz para a política. A relevância do pensar sobre o espaço justifica-se a partir das ações humanas e das práticas sociais (WERLEN, 2012). Desta maneira, tem-se na perspectiva experiencial um caminho para propor uma inextricável relação entre Ser e aparência com o sentido de espaço, justificando a análise anterior sobre as relações entre a realização do Dasein, saberes e experiência. A compreensão do fenômeno do espaço passa necessariamente pelas proposições explicativas a respeito de processos e relações que nos permitem identificar a espacialidade inerente à existência humana.

Nem o espaço é parte do agente e nem o agente observa e o significa como se o espaço estivesse num contêiner e fosse essencialmente geométrico (WERLEN, 2000). As explicações de Santos (2008) ao considerar o espaço um híbrido e a de Massey (2013), de pensar o espaço a partir de outros pressupostos e, portanto ressignificá-lo, são entendidas aqui como complementares. Ao compreender a ação política como possuidora de sentidos e fundamento geográficos, a Geografia deve manter entre suas preocupações ontológicas e epistemológicas as interações e as relações entre espaço e ação, com ênfase em seus desdobramentos para a política e para o viver social.

Nesse sentido, quando Arendt (2014) qualifica a ação como sendo processual, a noção de espaço em Massey (2013) também o é, pois,

[...] imaginar o espaço como sempre em processo, nunca como um sistema fechado, implica insistência constante, cada vez maior, dentro dos discursos políticos, sobre a genuína abertura do futuro. [...] O espaço jamais poderá ser essa simultaneidade completa, na qual todas as interconexões já tenham sido estabelecidas e no qual todos os lugares já estão ligados a todos os outros. (MASSEY, 2013, p.31 e 32).

Entendem-se as geograficidades como construídas nas, e pelas relações e interações entre o Ser e o mundo no conviver cotidiano, e dentro de um viver social instituído. Isso permite acompanhar sua dinâmica processual, pois como ela ocorre na, e pela ação, seus sentidos residem nas geograficidades que ali coexistem. A partir disso, Werlen (2012, p.569) chama a atenção para a necessidade das pesquisas geográficas analisarem "[...] a construção significativa de realidades geográficas e suas implicações para a constituição de sociedades e culturas.". Esses estudos são fundamentalmente relativos à nossa interação com a natureza e às transformações geradas dessa interação: "[...] relações espaciais socialmente construídas e suas implicações para a construção do mundo social [...]" (WERLEN, 2012, p.576).

Como a própria Massey (2013) reflete, as distintas trajetórias coexistentes no espaço, ao manter relações e interações humanas no cotidiano, permitem ao mesmo tempo a ligação do ser humano com a Terra, com o solo natural, e criar elos afetivos e interativos presentes na essência do sentido atribuído por Dardel (2011) ao termo géographicité; geograficidade. "O ser do ente que de imediato vem-de-encontro é mostrado fenomenologicamente pelo fio-condutor do cotidiano ser-no-mundo [...]" (HEIDEGGER, 2012, p.207). Deste modo, as ações humanas e as práticas sociais passam a ser os fenômenos centrais para o pensamento e o fazer geográficos quando preocupados em compreender e refletir sobre a ação política e seus sentidos evidenciados nas e pelas geograficidades.

A dimensão espacial da existência e as relações e interações que nela se realizam pertencem à realidade intersubjetiva e refletem-se por meio das geograficidades construídas no cotidiano do serno-mundo. Assim, a instituição de um viver social "[...] é uma rede simbólica, socialmente sancionada, onde se combinam em proporções e em relações variáveis um componente funcional e um

$\begin{array}{llllll}\text { Caminhos de Geografia } & \text { Uberlândia - MG } & \text { v. 19, n. 67 } & \text { Set/2018 } & \text { p. 83-98 } & \text { Página } 95\end{array}$


componente imaginário." (CASTORIADIS, 1982, p.159). Tais componentes coexistem compondo fenômenos constitutivos das coletividades humanas e dependem das coincidências nos desejos de convivência (MATURANA, 1997), pois são elas que conservam modos de existir do ser-no-mundo-ecom-o-mundo.

Isso permite afirmar que não é possível compreender o conjunto e a dinâmica da vida social como um sistema funcional apenas; é necessário e essencial alcançar as significações e os simbolismos nascidos, não de uma motivação funcional, mas espiritual, cognitiva ou emotiva. Todavia, entende-se conter nas geograficidades os elementos que proporcionam a compreensão da relação do ser-nomundo e ser-no-espaço com sua existência se realizando e sendo compartilhada com outros transcendendo para além dos limites do funcional apenas.

As reflexões e estudos de Eric Dardel (2011) permitem justificar e compreender a essencialidade das atividades do espírito, da experiência cognitiva e existencial e da ação para os estudos sobre as geograficidades. Esses estudos se desdobram nos processos de significação e intencionalidades atribuídas por meio do reconhecimento e da legitimação de espaços para a realização das ações políticas. Os sentidos geográficos da ação repousam nas geograficidades dos agentes-sujeitos responsáveis por essa ação e o seu fundamento está na espacialidade intrínseca ao agir em concerto.

\section{CONSIDERAÇÕES FINAIS}

A busca neste artigo esteve centrada na consideração e na compreensão da existência de um continuum experiencial e existencial entre a ação política e o viver social, realizada a partir do sentido e do fundamento geográficos de ambos os fenômenos. A preocupação ontológica da geografia com os fenômenos realizáveis e observáveis na e pela dimensão espacial da existência e da coexistência humanas, Ihe oferece um arcabouço teórico e epistemológico essencialmente ligado a fenomenologia da política e do viver social, cuja complementariedade deu-se, neste caso, com a ciência da cognição e suas explicações sobre o conhecer e a vida cotidiana. Se a ontologia humana versa sobre um sentido de Ser, então a cognição, e suas correlações com o processo do conhecer que se realiza no cotidiano, é fundamental para compreender como se dá a experiência vivida que define e caracteriza nossa coexistência.

O pensamento geográfico e suas preocupações com a ontologia e um sentido para o espaço implicam numa aproximação ante a experiência e existência humanas. Tais fenômenos propiciam a atribuição de significado, e ao mesmo tempo criam a perspectiva conceitual e filosófica para espaço. A dimensão da realidade intersubjetiva, que confirma a sua existência, depende da dinâmica cognitiva humana e das atividades do espírito no desenvolvimento e na realização das experiências, as quais oportunizam-nos construir explicações sobre essas mesmas experiências a partir da sua compreensão. Tudo isso é cotidiano, e depende das nossas relações e interações espaciais serem essencialmente cognitivas. $\mathrm{O}$ espaço e a espacialidade começam a adquirir sentido à vida humana nos primeiros movimentos do corpo quando criança, e o processo de complexificação desse sentido acompanha o desenvolvimento de um sentido para o Ser na realização de sua ontologia e existência.

O universo da cognição humana é abrigo, e ao mesmo tempo contém geograficidades e espacialidades alicerçadas em nossas intersubjetividades, na imaginação e na memória. Toda essa dinâmica e processos internos ao Ser encontrou no pensamento reflexivo e nos saberes meios de tornar consciente sua presença na vida cotidiana. Logo, a dimensão espacial é imprescindível, pois ela compõe tudo o que dá concretude e segurança às vidas social e política da espécie humana. Os territórios e os lugares, somados às geograficidades e espacialidades que lhes dão sentido e fundamento, têm na ação política uma atividade inerente à condição humana de existência e na Geografia a ciência que se preocupa com as relações e interações humanas para com o espaço e suas variações experienciais. A ação política, que revela o Ser do agente ao agir, tem na espacialidade intrínseca à realização desse Ser em sua coexistência cotidiana seu fundamento e nas geograficidades, que é também peculiar ao Ser, seu sentido.

A partir do instante que o pensamento geográfico passou a ter a dialética como um dos princípios básicos do pensar e fazer geográficos, um ambiente favorável a complexificação do entendimento proposto e realizado sobre o fenômeno do espaço, e seus processos gerativos e constitutivos, permitiu à geografia assumir a influência da política nesse processo, e com isso atribuir outro status para o fenômeno, ao compreendê-la como essencial para a formação e a produção do espaço geográfico. Como o fenômeno da política nos impõe compreender as relações e interações do

$\begin{array}{llllll}\text { Caminhos de Geografia } & \text { Uberlândia - MG } & \text { v. 19, n. 67 } & \text { Set/2018 } & \text { p. 83-98 } & \text { Página } 96\end{array}$


espaço onde ela se realiza, o entendimento de suas correlações com o viver social trouxe para o pensamento geográfico a ampliação das variáveis utilizadas em proposições explicativas sobre a dimensão espacial do cotidiano.

A compreensão de um sentido de espaço, a partir de um sentido de Ser em sua espacialidade e geograficidade intrínsecas, permite, ao correlacionar com a ação política, perceber a essencialidade da vida cotidiana para a realização dessa trama de reciprocidades e cumplicidades. Isso justifica as correlações e a interface entre o universo e a circunstancialidade da política e do viver social, para a maneira como pensamos o espaço e agimos nele e a partir dele. As espacialidades e as geograficidades condicionam a realização da ação política, e o viver social lhe dá sentido e abrigo. Ora, se o agir político ignora o contexto social a partir do qual se materializa, seus caminhos percorridos e êxitos alcançados tendem a ignorar o contexto de intersubjetividades, com seus significados criados e significantes estabelecidos, e que marcam e encerram aquele viver social instituído.

Toda a ação, quando se pretende política, tem nas espacialidades e nas geograficidades de cada Ser que dela participa sua principal força e motivo de realização. A política, em suas dimensões institucional e do cotidiano, é forjada no viver social instituído. A permanência de algo coletivamente estabelecido como um sistema social é causa e desdobramento do agir político, este necessariamente precedido por este conjunto de circunstancialidades de relações e interações entre as pessoas e entre as pessoas e o mundo.

\section{REFERÊNCIAS}

ARENDT, Hannah. A dignidade da política: ensaios e conferências. Tradução de H. Martins et. al. Rio de Janeiro: Relume e Dumará, 1993.

A vida do espírito - Vol. I o pensar. Tradução de João C. S. Duarte. Lisboa - Portugal: Instituto Piaget, 2000a.

A vida do espírito - Vol. Il o querer. Tradução de João C. S. Duarte. Lisboa - Portugal: Instituto Piaget. 2000b.

2007.

O que é política? $7^{a}$ ed. Tradução de Reinaldo Guarany. Rio de Janeiro: Bertrand Brasil, 2007.

Entre o passado e o futuro. 6ª ed. Tradução de Mauro W. Barbosa. São Paulo: Perspectiva,

A condição humana. $11^{\mathrm{a}}$ ed. Tradução de Roberto Raposo. Rio de Janeiro: Forense Universitária, 2014.

BACHELARD, Gaston. A poética do espaço. Tradução de Antônio de Pádua Danesi. São Paulo: Martins Fontes, 1989.

BESSE, Jean-Marc. Geografia e existência: a partir da obra de Eric Dardel. In.: DARDEL, Eric. 0 homem e a Terra: natureza da realidade geográfica. Tradução de Werther Holzer. São Paulo: Perspectiva, 2011. p. $111-139$.

BOHM, David. Diálogo: comunicação e redes de convivência. Tradução de Humberto Mariotti. São Paulo: Palas Athena, 2005.

CASTORIADIS, Cornelius. A instituição imaginária da sociedade. $5^{\text {a }}$ ed., Tradução de Guy Reynaud. Rio de Janeiro: Paz e Terra, 1982.

Figuras do pensável: as encruzilhadas do labirinto Vol. VI. Tradução de Eliana Aguiar. Rio de Janeiro: Civilização Brasileira, 2004.

CLAVAL, Paul. A revolução pós-funcionalista e as concepções atuais da geografia. In.: MENDONÇA, F. e KOZEL, S. (orgs). Elementos de epistemologia da geografia contemporânea. Curitiba: Ed. UFPR, 2002. p. $11-43$.

DARDEL, Eric. O homem e a Terra: natureza da realidade geográfica. Tradução de Werther Holzer. São Paulo: Perspectiva, 2011.

FREIRE, Paulo. A pedagogia do oprimido. 41를 ed., Rio de Janeiro; Paz e Terra, 2005.

$\begin{array}{llllll}\text { Caminhos de Geografia } & \text { Uberlândia - MG } & \text { v. 19, n. } 67 & \text { Set/2018 } & \text { p. 83-98 } & \text { Página } 97\end{array}$


HEIDEGGER, Martin. Ser e tempo. Tradução de Fausto Castilho. Ed.UNICAMP e Vozes: CampinasSP e Petrópolis-RJ, 2012.

MASSEY, Doreen. Filosofia e política da espacialidade: algumas considerações. Tradução de Rogério Haesbaert. GEOgraphia, № 12, Rio de Janeiro: 2004, p.7-23.

Pelo espaço: uma nova política da espacialidade. $4^{\underline{a}}$ ed. Tradução de Hilda Pareto Maciel e Rogério Haesbaert. Rio de Janeiro: Bertrand Brasil, 2013.

MATURANA, H. e VARELA, F.. A arvore do conhecimento: as bases biológicas da compreensão humana. Tradução de Humberto Mariotti e Lia Diskin. São Paulo: Palas Athena, 2001.

MATURANA, Humberto. A ontologia da realidade. Tradução de Cristina Magro et. al.. Belo Horizonte: Ed.UFMG, 1997.

Emoções e linguagem na educação e na política. Tradução de José F. C. Fortes. Belo Horizonte: Ed.UFMG, 1998.

Cognição, ciência e vida cotidiana. Tradução de Cristina Magro e Victor Paredes. Belo Horizonte: Ed.UFMG, 2001.

MERLEAU-PONTY, Maurice. Conversas - 1948. Tradução de Fábio Landa e Eva Landa. São Paulo: Martins Fontes, 2004.

PÁDUA, Lígia T. S.. A "topologia do ser": lugar, espaço e linguagem no pensamento de Martin Heidegger. 2005, 300f. Tese (Doutorado em Filosofia) - Depto de Filosofia da Pontifícia Universidade Católica - PCU-RJ, Rio de Janeiro: 2005.

PHILO, Chris. História, geografia, e o "mistério ainda maior" da geografia histórica. In: GREGORY, D.; MARTIN, R. e SMITH, G. (orgs). Geografia humana: sociedade, espaço e ciências sociais. Tradução de Mylan Isaack. Rio de Janeiro: Jorge Zahar Editor, 1996. p. 269 - 298.

SANTOS, Milton. A natureza do espaço: espaço e tempo, razão e emoção. $4^{\mathrm{a}}$ ed., São Paulo: EdUSP, 2008.

SCHUTZ, Alfred. Sobre fenomenologia e relações sociais. Tradução de Raquel Weiss. PetrópolisRJ: Vozes, 2012.

SOJA, Edward. Geografias pós-modernas: a reafirmação do espaço na teoria social crítica. Tradução de Vera Ribeiro. Rio de Janeiro: Jorge Zahar Editor, 1993.

WERLEN, Benno. Entrevista Benno Werlen. Revisor dos textos Fabio Betioli Contel. Boletim Campineiro de Geografia, v.2, ํㅜ 3, 2012, p.547 - 576.

Regionalismo e sociedade política. Tradução de Rogério Haesbaert. Revista GEOgraphia, ano II, no 4, 2000, p.7 - 25.

Recebido em: 11/09/2017

Aceito para publicação em: 12/06/2018 